\title{
Categorias de autocuidado entre pessoas idosas com diabetes: estudo sociopoético
}

\author{
Categories of self-care among older adults with diabetes: a sociopoetic study \\ Categorías de autocuidado entre ancianos con diabetes: estudio sociopoético
}

\author{
Iraci dos Santos'; Renata Gomes Machado Guerra ${ }^{\text {II }}$ Leandro Andrade da Silva ${ }^{\text {III }}$
}

\begin{abstract}
RESUMO: Teve-se como objetivo identificar as categorias de autocuidado apresentadas por pessoas idosas com diabetes, considerando suas dimensões física, mental e espiritual. Método sociopoético, aplicando as fases do grupo-pesquisador formado por 10 participantes da pesquisa e curso de autocuidado, que desenvolveram a técnica artística Vivência do corpo como território mínimo, utilizando o desenho livre, em 2012, no Rio de Janeiro-Brasil. Nos resultados ressaltam-se as categorias: dificuldades de autocontrole na convivência com o diabetes; autocuidado para elevar a autoestima; otimismo e perseverança no cuidado com o diabetes; cuidar do corpo e mente; entender a importância da convivência com a família. Concluiu-se que apesar do autocuidado relacionado à enfermidade, os indivíduos idosos têm dificuldade para restringir a ingestão de açúcares e carboidratos. Então, a promoção do autocuidado por profissionais capacitados, visando à construção coletiva de conhecimentos e o planejamento de ações voltadas para essa meta, torna-se prioridade das políticas públicas de saúde às pessoas idosas.
\end{abstract}

Palavra-Chave: Enfermagem; autocuidado; gerontologia; pesquisa qualitativa.

\begin{abstract}
This study sought to identify categories of self-care among older adults with diabetes, considering their physical, mental and spiritual dimensions. The sociopoetic method was applied via the stages of the researcher-group, consisting of 10 participants in the self-care course and research, who engaged in the artistic technique Experiencing the body as a minimum territory using free drawing, in 2012, in Rio de Janeiro, Brazil. Prominent among the results were the categories: difficulties in self-control in living with diabetes; self-care to raise self-esteem; optimism and perseverance in caring for diabetes; caring for body and mind; and understanding the importance of living with the family. It was concluded that, despite diabetes-related self-care, older adults have difficulty restricting their intake of sugars and carbohydrates. Accordingly, public health policies for older adults should make a priority of self-care promoted by trained professionals, with a view to constructing knowledge collectively and planning actions for this purpose.
\end{abstract}

Keyword: Nursing; self-care; gerontology; qualitative research.

RESUMEN: El estudio tuvo como objetivo identificar las categorías de autocuidado de ancianos con diabetes, considerando sus dimensiones físicas, mentales y espirituales. Método sociopoético aplicando las etapas del grupo investigador compuesto por 10 participantes de la investigación y curso de autocuidado que desarrollaron la técnica artística La experiencia del cuerpo como territorio mínimo, utilizando diseño libre, en 2012, en Rio de Janeiro- Brasil. Se destacaron las categorías: dificultades de autocontrol en la convivencia con la diabetes, autocuidado para elevar la autoestima, el optimismo y la perseverancia en el cuidado de diabetes, el cuidado del cuerpo y mente, entender la importancia del convivio con la familia. Se concluye que, a pesar del autocuidado relacionado con la enfermedad, los ancianos tienen dificultades en restringir la ingesta de azúcares y carbohidratos. Entonces, la promoción del autocuidado por profesionales capacitados, con vistas a la construcción colectiva de conocimientos y de la planificación de las acciones volcadas hacia ese objetivo, se vuelve prioridad de las políticas de salud pública para los ancianos.

Palabras-Clave: Enfermería; autocuidado; gerontología; investigación cualitativa.

\section{INTRODUÇÃO}

A atuação do enfermeiro junto às pessoas idosas com diabetes, centrada na orientação para o autocuidado (AC), é necessária. Geralmente, elas possuem conhecimentos limitados para conviverem com essa doença, descuidando-se quanto aos hábitos de vida referentes à dieta, atividades físicas e autoadministração da terapia medicamentosa.
Aqui, ressalta-se, o crescimento demográfico da população idosa, no Brasil, a partir dos anos 60 , alterando significativamente a pirâmide populacional ${ }^{1}$. Considerando que o despreparo das pessoas e as dificuldades para enfrentar o $\mathrm{AC}$ podem conduzir à comorbidades, pressuõe-se que a orientação de enfermagem para o autocuidado conduzirá aos estilos de vida com qualidade.

'Doutora em Enfermagem. Professora Titular e. Professora Visitante do Departamento Fundamentos de Enfermagem e do Programa de Pós-Graduação da Faculdade de Enfermagem da Universidade do Estado do Rio de Janeiro. Brasil.E-mail: iraci.s@terra.com.br

IIMestre em Enfermagem pelo Programa de Pós-Graduação da Faculdade de Enfermagem da Universidade do Estado do Rio de Janeiro. Enfermeira Tenente da Polícia Civil do Estado do Rio de Janeiro. Brasil. E-mail: renatagomesmv@gmail.com

IIIEnfermeiro. Terapeuta Ocupacional. Doutorando do Programa de Pós-Graduação da Faculdade de Enfermagem da Universidade do Estado do Rio de Janeiro. Professor do Instituto Castelo Branco do Rio de Janeiro. Brasil. E-mail: proflandrade@gmail.com 
Diante do aumento dessa população, associado às doenças crônicas não transmissíveis, importa implementar programas educativos às pessoas idosas, favorecendo-lhes o ensino do AC à saúde, prevenindo incapacidades e postergando a morte ${ }^{2}$. Assim, o enfermeiro atua no processo de educar/cuidar do indivíduo com diabetes para informar e esclarecer dúvidas sobre a doença, investigando e avaliando suas limitações e de sua família, visando prevenir os agravos decorrentes desta enfermidade.

Os componentes do cuidar são subsídios para a sistematização das ações de enfermagem, entendendose que o enfermeiro atende as necessidades humanas, considerando-se as dimensões corporais física, mental e espiritual, constituintes da integralidade do $\operatorname{ser}^{3}$. Releva-se, ainda, que o controle eficaz dos índices glicêmicos e consequente prevenção das complicações dessa enfermidade relacionam-se ao AC. Pois a verificação dos níveis glicêmicos, administração correta dos medicamentos e da insulina, e a alimentação saudável são importantes para a adequação desse controle.

O enfermo idoso possui, geralmente, limitações referentes à: visão diminuída, perda da audição, déficit de memória, mobilidade e coordenação motora fina diminuída, tremores aumentados, depressão e solidão, além de outras doenças clínicas, e recursos financeiros diminuídos ${ }^{4}$. Ele é mais suscetível a agravos, visto lidar com problemas nos aspectos fisiológicos, psicológicos e sociais decorrentes do processo de senescência. Por isso, são usuários assíduos do sistema de saúde.

Para conhecer a situação atual do preparo de pessoas idosas para conviver com diabetes, realizouse uma busca em bases de dados da Biblioteca Virtual em Saúde (BVS), e no Scientific Electronic Library Online (SCIELO), utilizando os descritores: idoso, Diabetes Mellitus e autocuidado, e os critérios de inclusão - artigos completos; publicações no período de 2000 a 2012 nos idiomas português, espanhol e inglês.

Entre 1358 trabalhos encontrados, 232 foram selecionados, porque atenderam aos critérios mencionados. Desses, 21 foram encontrados no Literatura Latino-Americana e do Caribe em Ciências da Saúde (LILACS) e 211 na Medical Literature Analysis and Retrieval System Online (MEDLINE). Descreve-se uma síntese dos resultados dessa busca.

Para promover mudanças de comportamento, as orientações aos enfermos englobam aspectos subjetivos, emocionais, econômicos, sociais e culturais, pois influenciam a prática de autocuidado. Sua capacitação referente ao engajamento depende da parceria com profissionais de saúde e de outras áreas do conhecimento, tais como: direito, sociologia, economia, psicologia e arquitetura. Acredita-se que jamais se alcançará o AC sem essa participação intersetorial efetiva ${ }^{5}$.

A convivência com a enfermidade em questão, por si só, traz ao cliente muitas restrições e alterações no padrão de vida. Somadas ás necessidades do tratamento, devido ao processo de envelhecimento, sobreleva-se a redução do sentido de liberdade e de bem viver. Portanto, o indivíduo idoso deixa de ser um objeto de tratamento, para tornar-se um cidadão com direito à decisão, e opinião, interessado em buscar o melhor para si, capacitado para realizar ações de cuidado dentro de suas limitações ou dependências impostas pela patologia 5 .

Existe influência do nível de instrução e da renda familiar, no entendimento e adesão ao autocuidado por parte da pessoa idosa com diabetes. Trata-se de um dos fatores que figura entre as dificuldades encontradas no controle e tratamento dessa doença, pois a dieta alimentar e os medicamentos, quando não oferecidos pelo serviço de saúde, significam um acréscimo nas despesas familiares ${ }^{6}$. Então, sua renda e/ou da sua família influencia o seu autocuidado.

Foram caracterizados clientes com diabetes segundo variáveis sociodemográficas e econômicas, descrevendo-se condições de saúde, capacidade funcional e utilização dos serviços de saúde. Em todas as atividades de vida diárias (AVDs) obteve-se percentual de dependência, ou seja, os sujeitos não conseguem realizá-las, e necessitam ajuda de terceiros? ${ }^{7}$.

Outra publicação, alerta que o profissional deve ter conhecimento sobre o envelhecimento e as limitações do sujeito idoso, a fim de cuidar e educá-lo corretamente e aos familiares ${ }^{8}$.

Verificando-se, nessa busca em base de dados, a inexistência de trabalhos com enfoque na orientação de enfermagem ao AC, junto à pessoa idosa, e suas modalidades de cuidados para conviver com diabetes, delimitou-se o problema: quais são as categorias de autocuidado apresentadas por pessoas idosas, visando conviver com diabetes?

Teve-se como objetivo identificar as categorias de autocuidado apresentadas por pessoas idosas com diabetes considerando suas dimensões física, mental e espiritual.

\section{Referencial Teórico-Metodológico}

Escolheu-se o método sociopoético, qualitativo, descritivo. Inserida no paradigma das ciências humanas e sociais, a sociopoética, uma filosofia e prática de cuidar, educar, pesquisar, institui a construção coletiva de conhecimento9.

$O$ caminho do pesquisador fundamenta-se teoricamente em: Pedagogia do oprimido de Paulo Freire, contribuinte ao desenvolvimento das seis etapas de pesquisa do Grupo-Pesquisador (GP), dispositivo analítico desse método; Análise institucional, tendência René Lourau, principalmente os conceitos de dispositivo, e de analisador; Escuta mitopoética de René Barbier, onde a escuta e o silêncio dão o ritmo do 
processo de criação das pessoas; Teatro do oprimido de Augusto Boal, considerando suas experiências de dramatizações para expressar saberes gestuais, escondidos, recalcados; e a Esquizo-análise de Gilles Deleuze e Felix Guattari ${ }^{9}$, relevando-se a noção de devir destes autores.

Na sociopoética, o GP produz os dados de pesquisa junto ao pesquisador institucional, que atua como facilitador, aplicando os seguintes princípios filosóficos da sociopoética: $\mathrm{O}$ corpo é fonte de conhecimento; O GP é coprodutor do conhecimento; Na leitura dos dados da pesquisa são favorecidas as culturas de resistência e dominadas; Valoriza-se o papel da criatividade de tipo artístico no aprender, no conhecer e no pesquisar; É importante o sentido ético, espiritual, e humano das formas e dos conteúdos na construção dos saberes. Ressalta-se que no desenvolvimento do método escolhido há aplicação simultânea dos seus fundamentos teóricos e princípios filosóficos ${ }^{9}$.

Para campo de pesquisa, optou-se pela Universidade Aberta para a Terceira Idade, da Universidade do Estado do Rio de Janeiro. Quanto à composição do GP, buscou-se nessa instituição o contato de indivíduos idosos que atendessem ao critério de inclusão: idade superior ou igual a 60 anos, oficialmente cadastrado, em acompanhamento no ambulatório do Núcleo de Atendimento ao Idoso; aceitar participar da pesquisa/ curso de autocuidado para convivência com diabetes, assinar o Termo de Consentimento Livre e Esclarecido (TCLE); e ter diabetes. Critérios de exclusão: ter deficiência visual e /ou motora impossibilitando seu autocuidado; impossibilidade de locomoção. Somente 10 pessoas atenderam aos critérios estabelecidos.

Através do método sociopoético desenvolveu-se, em 2012, as seis fases/oficinas sociopoéticas: Instituição do GP; Investigação temática (negociação do tema apresentado pelo pesquisador institucional e/ ou escolha da questão norteadora da pesquisa, agendamento dos dias, horários e local para a realização da pesquisa); Oficinas sociopoéticas (precedidas de dinâmicas de sensibilidade e relaxamento) para ministração do curso de autocuidado e desenvolvimento da investigação, ou seja, da produção de dados através da técnica Dinâmica do Corpo como Território Mínimo (DCTM), análise inicial dos dados produzidos junto ao GP; apresentação ao GP da análise dos dados produzidos, pelo (s) facilitador (es); Contra análise dos dados produzidos pelo GP; Validação dos conhecimentos produzidos pelos copesquisadores; Socialização dos resultados obtidos e avaliação das oficinas sociopoéticas.

No curso de autocuidado para convivência com diabetes, o GP foi orientado sobre: cuidados com o corpo, ressaltando os cuidados com os pés, oferecendose, inclusive, um folder obtido na internet acerca deste assunto; exercícios físicos; possibilidades de lazer; dieta específica, fornecendo-se, uma receita para restrição de açúcar cedida por nutricionista. Foi, também, oferecido lanche com dieta light em todas as oficinas.

Aplicou-se a técnica artística de desenho livre para desenvolver a DCTM $^{10}$, considerando as questões orientadoras: como eu me cuido para viver com bem-estar? Quais são as minhas preferências de alimentação, considerando a diabetes e o autocuidado? Quais atividades de AC eu desenvolvo? O que preciso saber para me cuidar convivendo com diabetes? Cada criação, expressa no desenho do corpo, foi analisada pelo próprio copesquisador (participante dos estudo) e, em seguida, por ele, explicitada por escrito. Tais descrições foram colocadas e/ou anexadas nos desenhos.

A pesquisadora e os facilitadores da pesquisa analisaram os desenhos comparando-os às descrições dos copesquisadores e às respostas destes às questões formuladas para elaboração do desenho na DCTM. De cada desenho delimitou-se temas individuais, reveladores da estrutura de pensamento dos copesquisadores. Neste trabalho, a análise categorial dos subtemas grupais propiciou a delimitação de categorias temáticas, compondo o estudo sociopoético classificatório. Ainda foram se destacadas as dicotomias, as oposições nos dados produzidos, alternativas e escolhas existentes no conjunto das produções do GP9.

O desenvolvimento desta pesquisa foi aprovado pela Comissão de Ética em Pesquisa da UERJ, Protocolo $\mathrm{n}^{\circ}$ 033.3.2012, respeitando-se as normas descritas na Resolução no 466/2012, que enfatiza o compromisso ético com os participantes da pesquisa. O GP assinou o TCLE e concordou com a divulgação de suas respostas às questões norteadoras da pesquisa, se respeitada sua privacidade.

Os depoimentos obtidas foram identificados pela designação Copesquisador A, Copesquisador B... Copesquisador J.

Uma limitação do estudo refere-se ao fato de ele ser um recorte da dissertação de mestrado, no qual somente são apresentados os resultados obtidos com uma das três técnicas de pesquisa utilizadas no desenvolvimento da dissertação.

\section{Resultados e Discussão}

As categorias temáticas emergentes deste estudo são analiasadas a seguir.

\section{Dificuldades de autocontrole na convivência com o diabetes}

Esta categoria emergiu dos subtemas: insegurança, fragilidade e dificuldade no controle, reveladoras da fragilidade da pessoa idosa em relação ao seu viver com a saúde prejudicada por diabetes:

Me sentia bem para minha idade. Era muito dinâmica. Depois da queda que tive me sinto fraca, sem força para 
andar. Estou deprimida. Estou muito magra. Estou pele e osso. Essa fraquesa que sinto nas pernas é por causa do diabetes. Nem posso andar sozinha. (Copesquisadora A)

A síndrome da fragilidade refere-se à síndrome biológica, qual seja a dimensão corporal física, caracterizada por diminuição da reserva homeostática e redução da capacidade do organismo resistir ao estresse, resultando em declínios cumulativos em múltiplos sistemas fisiológicos, causando vulnerabilidade e efeitos adversos ${ }^{7}$. Nesse depoimento intuiu-se haver tristeza com a aparência física pessoal e a diminuição da independência, transmitindo a incerteza, insegurança e incapacidade de exercer com autonomia e convicção o controle da própria vida ${ }^{3,10,11}$.

Alterações fisiológicas e dificuldades enfrentadas por pessoas idosas e seus familiares são consideradas estranhas, e ao mesmo tempo em que, fragilidade e ser frágil são objetivados como adoecimento, fraqueza e risco de sofrer quedas ${ }^{8}$. Se essa participante identifica suas dificuldades e planeja estratégias para executar uma conduta de saúde, ela coloca em prática a autoeficácia percebida, destacada na Teoria Modelo de Promoção da Saúde de Nola Pender ${ }^{12}$.

\section{Autocuidado para conviver com diabetes e elevar a autoestima}

Formada pelos subtemas controle, autocuidado e autoimagem, esta categoria aponta a tranquilidade da copesquisadora no cuidado e controle de diabetes, demonstrando a preocupação com as consequências do mau controle.

Procuro me cuidar. Não consigo mais fazer as coisas como antes. Adoro comer de tudo, mas tento seguir dieta. Consigo me controlar para não comer muito. Consigo manter meu peso e cuidar do meu diabetes. Não quero ter outros problemas. Me cuido para me sentir bem e bonita. (Copesquisadora B)

Aqui se ratifica o conceito de autoimagem, a representação de nosso corpo formada em nossa mente, o modo pelo qual ele se apresenta para nós mesmos ${ }^{10,13}$. Corrobora-se que a imagem corporal é o retrato que cada um faz de si. Podendo sofrer interferências como doenças, limitações e envelhecimento ${ }^{11}$.

\section{Otimismo e perserverança no cuidado com o diabetes}

Foram delimitados nessa categoria, os subtemas otimismo para viver; perseverença ao conviver com diabetes; e cuidado com o adoecimento. Uma copesquisadora demonstra otimismo e perspectiva de que tudo dará certo, voltando ao passado, à infância:

Foi uma época muito boa em minha vida e sinto saudades de comer as frutas no pé. Tenho dificuldade, hoje, de comer uma fruta só, porque comia várias, hoje sei que não posso. Sou diabética, mas me sinto bem e confiante que vou conseguir me cuidar. O desenho que fiz sou eu hoje em dia, feliz e bem. (Copesquisadora C)

O plano alimentar recomenda o consumo diário de duas a quatro porções de frutas, sendo uma delas rica em vitamina $\mathrm{C}$ e de três a cinco porções de hortaliças cruas e cozidas ${ }^{14}$. Observa-se que essa copesquisadora desconhece o cuidado necessário, porém busca esse conhecimento para se autocuidar. Autocuidado com o corpo exige da pessoa um aprendizado especial, visando à promoção da saúde e as mudanças produzidas pela doença e à prevenção de complicações ${ }^{13,14}$.

\section{Convivendo tranquilamente com o diabetes}

Nesta categoria foram delimitados os subtemas perseverança, cuidado, tranquilidade e dependência. Verifica-se, na descrição do desenho produzido por um copesquisador $\mathrm{D}$ tem uma vida tranquila, convive bem com sua doença e é perseverante:

Me sinto bem. Procuro cuidar do meu corpo, da minha vida da melhor maneira possível. Sigo tudo que a minha esposa fala, tomo os remédios que ela me dá, ela que sabe dos horários, ela que cuida de mim. Esse desenho sou eu pensando no dia de amanhã com todo orgulho e brio. Procuro viver minha vida com tranqüilidade. (Copesquisador D)

Esse depoimento ratifica que a dependência pode ocorrer em todas as idades, mas aumenta a prevalência quando a idade aumenta pelo aparecimento e desenvolvimento de doenças crônicas, que podem conduzir a diferentes tipos e níveis de dependência ${ }^{11}$. Nesse caso, vê-se que mesmo sendo capaz de realizar determinadas AVDs, o copesquisador necessita da ajuda da esposa, em tarefas como tomar os remédios no horário certo. Então, tornam-se necessárias a supervisão e a vigilância da cuidadora ${ }^{15}$.

\section{O peso do diabetes no viver}

Esta categoria é formada pelos subtemas: revolta, conformação, dificuldade no controle da alimentação e do autocuidado. Analisando-se as falas, percebe-se que uma copesquisadora se revolta com sua enfermidade, todavia se cuida, pois sabe das complicações decorrentes do descuido.

Diabetes é coisa do diabo. Por que existe essa doença? Não tem jeito temos que conviver. Deixo de ir a festas porque não posso comer. Quero comer de tudo, salgado e doce. Hoje me sinto melhor depois que emagreci. Não gosto de ser diabética, mas me cuido porque sei das consequências. (Copesquisadora E)

A dificuldade do controle alimentar apareceu constantemente nas falas do GP, pois a proibição de certos alimentos acaba gerando desânimo nas pessoas para ir a festas, podendo levá-las ao isolamento social e, assim, acaba evitando práticas de lazer.

Concorda-se que o lazer tem alto significado perante a sociedade, por ser fonte de criação cultural, 
de resgate do ser humano e de favorecimento de uma nova socialização ${ }^{12}$.

\section{Autocuidado sempre para viver mais e melhor}

Subtemas delimitados nesta categoria: equilíbrio, otimismo e autocuidado. A descrição do desenho demostra o cuidado que o copesquisador tem com o seu corpo ao fazer alusão ao equilíbrio da natureza. Revelou-se seu cuidado para manter a vida em equilíbrio, com tranqüilidade e bem-estar.

Sinto-me uma árvore porque gosto da natureza e gosto de mim e de me cuidar. Procuro sempre fazer a dieta. Prefiro nem provar o doce. Espero que achem a cura de diabetes. Enquanto isso, cuido para viver, cada vez mais. Cuido do meu corpo, da minha higiene. Faço os exames necessários e sempre quando tem algo errado na minha saúde, procuro logo o médico. (Copesquisador F)

Essa fala ratifica que as pessoas se comprometem a adotar condutas a partir das quais antecipam os benefícios derivados, valorizados de forma pessoal ${ }^{12,13}$. Desse modo, nota-se que o cuidado e a higiene com o corpo, associado ao bom hábito alimentar e ao lazer, tornam as AVDs mais tranquilas e equilibradas, melhorando o conforto/bem-estar.

\section{Entender a importância da convivência com a família}

Formaram esta categoria os subtemas desânimo, difícil controle da alimentação, e autocuidado. Observou-se que a copesquisadora aprecia comer e sente falta de comer o que quiser. Sabe da importância do exercício para o controle de diabetes, mas está desanimada para realizá-lo. Na descrição do seu desenho se evidenciou a importância da família:

Queria ir à festa junina com a minha filha e minha neta, que são a minha família. Adoro festa junina para comer as coisas gostosas. Gosto da música também. Procuro me cuidar, faço dieta apesar de gostar de comer de tudo. Estou sem ânimo para fazer exercício físico. Tenho que me controlar para não comer doce. Seria muito bom se achassem a cura para o diabetes. (Copesquisadora $\mathrm{G}$ )

A família, juntamente com a sociedade e o Estado têm o dever de assegurar ao indivíduo idoso todos os direitos da cidadania, garantindo sua participação na comunidade, defendendo sua dignidade, bem-estar e o direito à vida ${ }^{8}$. O apoio familiar é importante no processo de envelhecimento, haja a vista a relação de afeto e segurança. Em alguns casos essa relação também poderá ser financeira, de ajuda ou até mesmo de dependência.

\section{Autocuidado com o corpo e com a mente}

Analisando a descrição do desenho livre do qual foram delimitados os subtemas autoestima, autocuidado e autoimagem, ressaltam-se o sucesso e a felicidade com o cuidado, nesta categoria. A autoestima e a autoimagem são fortes traços no cuidado com o corpo, destacando-se principalmente no vestuário, acessórios e maquiagem:

Procuro e gosto de me cuidar. Saio sempre maquiada e arrumada com alto astral. Só não consigo usar salto muito alto para não doer o joelho. Quando fiquei diabética fiquei chateada, mas não adianta, por isso procurei me cuidar para não piorar. Faço tudo para me cuidar e sempre de bem com a vida. Adoro sair, conhecer pessoas, trocar informações. Adoro comer, mas me controlo bem. (Copesquisadora $\mathrm{H}$ )

As condutas promotoras de saúde, através da alimentação, da atividade física e da ocupação do tempo em atividades variadas, enfatizam a condição desejável para a harmonia do corpo. $O$ estilo de vida ativo é fundamental na promoção da saúde. A adoção de condutas promotoras de saúde refere-se à conduta prévia relacionada, que, assumindo efeitos diretos e/ou indiretos, constitui uma probabilidade para o alcance de resultados ${ }^{12,13,16}$. Assim como os demais copesquisadores, esse membro do GP valoriza a busca de novos conhecimentos para cuidar do corpo/saúde e aprender coisas novas.

\section{Descuidado consciente}

Nesta categoria, foram delimitados os subtemas: dificuldade no controle da alimentação e descuido. Percebeu-se que a copesquisadora tem consciência do seu descuidado, inclusive com a prática de exercício físico. Sua insatisfação com o corpo, o ganho de peso e as dores nos joelhos a desmotivam para o autocuidado.

Minha diabetes é muito fajuta. Acabo comendo muito. Só gosto de coisas que não posso: chocolate, doce, fritura, nada saudável. Estou engordando, aí sinto muita dor nos joelhos. Queria muito que descobrissem a cura de diabetes. É muito ruim não poder comer as coisas. Não faço exercício, estando muito desanimada para andar. (Copesquisadora I)

Diante da autoimagem prejudicada, o corpo interfere no autocuidado, e se intensificam as dores articulares, impedindo a atividade física. Existe a possibilidade de sérios riscos de desenvolver mais comorbidades decorrentes do descontrole da diabetes. Recorda-se que a síndrome metabólica é responsável pela promoção de aterosclerose prematura e por riscos precoces da doença cardiovascular ${ }^{17}$.

\section{Vivendo sempre feliz}

Subtemas delimitados na última categoria: otimismo, dificuldade no controle da alimentação e autocuidado. Na seguinte descrição do desenho, destacam-se a autoestima e o autocuidado.

Essa sou eu, sempre feliz! Sinto-me realizada e agradeço a Deus. Consigo controlar o diabetes. Cuido-me, faço os exames e vou ao médico regularmente. Não queria ser diabética, na verdade ninguém gosta, mas sendo, tenho que me cuidar para viver mais. A maior dificuldade é controlar a boca. Agora tento seguir a dieta. (Copesquisadora J) 
Quando o cuidar se encontra na perspectiva da autoestima, pressupõe-se a utilização do corpo físico para um cuidar sutil, ou seja, uma espécie de alimento para o espírito, que favorece a promoção do autoconhecimento e do autocrescimento, buscando organizar forças subjetivas e/ou sociais que podem transformar o ser humano, e, consequentemente, o seu destino ${ }^{18,19}$.

\section{CONCLUSÃO}

O investimento nas políticas públicas de saúde voltadas para a população idosa, referentes à prevenção de doenças, pode contribuir para a promoção da saúde, aqui entendida como autocuidado, desde a faixa etária infantil e da adolescência. Tal investimento pode ser feito desde a capacitação de profissionais de saúde e de equipes interdisciplinares, para atuarem junto às pessoas, visando ao ensino/aprendizagem do autocuidado, para viver com bem-estar, mesmo em situações limitantes devido ao adoecimento.

Assim, foram respondidas as questões norteadoras desta investigação, alcançando-se a resposta (objetivo) do problema de pesquisa formulado, quais sejam, as categorias de autocuidado adotadas pelos membros do grupo-pesquisador, através do desenvolvimento da dinâmica do corpo como território mínimo.

Analisando as falas do GP, concluiu-se que os participantes receiam as complicações de diabetes, mas acreditam e torcem pela cura dessa enfermidade e, portanto, a esperança na cura sempre esteve presente entre eles.

Então, alerta-se para a importância da manutenção e/ou criação de grupos de cidadãos e cidadãs, que discutam e pesquisem temas tais como autocuidado para todos que tenham e/ou não uma convivência saudável. Dessa forma será possível construir a consciência necessária para se autocuidar em prol do bem-estar/ qualidade de vida.

\section{REFERÊNCIAS}

1.Kalache A. Envelhecimento no contexto internacional, a perspectiva da Organização Mundial de Saúde. In: Anais do 1ำ Seminário Internacional: Envelhecimento Populacional: uma agenda para o final do século. Brasília (DF): Ministério da Previdência e Assistência Social; 1996.

2.Ministério da Previdência e Assistência Social (Br). Política Nacional do Idoso: perspectiva governamental. Brasília (DF): Secretaria da Assistência Social; 1996.

3.Santos I dos, Caldas CP, Gauthier J. Erdmann AL, Figueiredo NMA. Cuidar da integralidade do ser: perspectiva estética/sociopoética de avanço no domínio de enfermagem. Rev enferm UERJ. 2012; 20: 4-9.

4.Brunner L, Suddarth DS. Tratado de enfermagem médico-cirúrgica. Rio de Janeiro: Guanabara-Koogan; 2009. 5.Lenardt MH, Hammerschmidt KSA, Borghi ACS, Vaccari E, Seima MD. O idoso portador de nefropatia diabética e o cuidado de si. Texto contexto enferm. 2008; $17(2): 313-20$.
6.Tavares DMS, Rodrigues RAP. Educação conscientizadora do idoso diabético: uma proposta de intervenção do enfermeiro. Rev esc enferm 2002; [citado em 17 mai 2009] 36(1): 88-96. Disponível em: http://www. scielo.br/scielo.php?script $=$ sci arttext $\&$ pid $=\mathrm{S} 0080$. $62342002000100013 \& \operatorname{lng}=$ en. doi: 10.1590/S0080. 62342002000100013

7.Oliveira LPBA, Menezes RMP. Representações de fragilidade para idosos no contexto da estratégia saúde da família. Texto contexto enferm USP. 2011; [citado em 09 out 2014] 20: 301-9. Disponível em: http://www. scielo.br/scielo.php?script $=$ sci_arttext\&pid $=\mathrm{S} 0104$ $07072011000200012 \& \operatorname{lng}=$ en. http://dx.doi. org/10.1590/S0104-07072011000200012.

8.Araujo I, Paul C, Martins M. Living older in the family context: dependency in self-care. Rev esc enferm USP online. 2011; [cited in 2014 Out 09] 45: 869-75. Disponível em: http://www.scielo.br/scielo.php?script =sci arttext\&pid =S0080-62342011000400011\&lng= en $\&$ nrm = iso http://dx.doi.org/10.1590/S0080 62342011000400011.

9.Gauthier J. O oco do vento-metodologia da pesquisa sociopoética e estudos transculturais. Curitiba (PR): Editora CRV; 2012.

10.Santos I dos, Jesus PBR, Brandão ES, Oliveira EB, Silva AV. Repercussões do acometimento cutâneo na vida das pessoas: sociopoetizando autoimagem e autoestima. Rev enferm UERJ. 2014;22: 157-62.

11.Meure ST, Benedetti TRB, Mazo GS. Aspectos da autoimagem e autoestima de idosos ativos. Motriz. 2009; 15:788-96.

12.Sakraida TJ. Nola Pender: modelo de promoção da saúde. In: Alligood MR, Tomey AM. Modelos y teorías en enfermería. $7^{\text {a }}$ ed. Barcelona (ES): Elsevier; 2011.p. 434-53 13.Alves CS, Santos I dos, Silva AFL, Caldas CP, Santana RS. O grupo-pesquisador construindo ações para o envelhecimento saudável:pesquisa sociopoética. Esc Anna Nery. 2011; 15: 746-54.

14.Sociedade Brasileira de Diabetes. Diretrizes. Tratamento e acompanhamento do diabetes mellitus. São Paulo: SBD; 2007.

15.Fried LP, Walston J. Frailty and failure to thrive. In: Hazzard WR, Blass JP, Halter JB, Ouslander JG, Tinetti ME. Principles of geriatric medicine and gerontology. 5th ed. Nova York: MacGraw-Hill; 2003.

16.Carvalho Filho ET, Papaléo Netto M. Geriatria: fundamentos, clínica e terapêutica. $2^{\text {a }}$ ed. São Paulo: Atheneu; 2006.

17.Lima CT, Kanno DT, Gonsalles MCR, Assis DMB, Gianesella EMF. Diabetes e suas comorbidades no Programa de Saúde da Família em Bragança Paulista. Rev Bras Clin Med 2010; 8:316-9.

18.Gauthier J, Hirata M. A enfermeira como educadora. In: Santos I dos, Figueiredo NMA, Duarte MJRS, Sobral VRS, Marinho AM. Enfermagem fundamental: realidade, questões e soluções. São Paulo: Atheneu; 2001. p.123-41

19.Guerra RGM. Convivência da pessoa idosa com diabetes buscando autonomia para o autocuidado: estudo sociopoético [dissertação de mestrado]. Rio de Janeiro: Universidade do Estado do Rio de Janeiro; 2013. 